\title{
RESPONSE OF GROWTH INDICES IN BLACK GRAM DUE TO RHIZOBIUM INOCULATION
}

\author{
S. K. Nitu* and S. A. Haider \\ Crop Physiology Laboratory, Department of Botany, \\ University of Rajshahi, Rajshahi 6205, Bangladesh
}

Key words: Growth indices, black gram, Rhizobium.

Black gram (Vigna mungo L. Hepper) locally known as 'Mashkalai' belongs to the family Leguminosae and it is extensively grown in both tropical and sub-tropical countries of the world. This crop may play important role in daily diets of the people of Bangladesh because of its high protein content (20-25\%), double of that of wheat and three times of that of rice (FAO, 1994). Experiments indicate that nodules on roots of legumes are responsible for fixing atmospheric nitrogen and Rhizobium plays an important role for nodulation in leguminous plants. Rhizobium also improves the yield significantly in many legume crops (David, 1991). The present study deals with the response of growth indices in two black gram varieties due to colonization by three different Rhizobium strains.

The experiment was conducted in the Department of Botany of Rajshahi University in the growing season of 2007 using earthen pots of $729.3 \mathrm{~cm}^{2}$ under open-air condition. Two varieties of black gram (BARI MASH-I and BINA MASHI) were procured from the Regional Pulse Research Station of Bangladesh Agricultural Research Institute (BARI), Ishurdi, Pabna and used as plant material. Three strains of Rhizobium ( $\mathrm{RV}^{\mathrm{m}}$ 301, $\mathrm{RV}^{\mathrm{m}} 302$ and $\mathrm{RV}^{\mathrm{m}}$ 303) were used for nodulation in rhizosphere of black gram and they were procured from Soil Science Division of BARI, Joydebpur, Gazipur. Soil for experimental pots were dried under sunlight and then it was made free from plant debris and other materials. The soil was mixed proportionately with compost and triple super phosphate (TSP) and muriate of potash (MP). It was sandy loam with the $\mathrm{pH}$ value of 7.5. The detailed methodology has been described by Nitu et al. (2009).

There were five treatments designated as $T_{1}$ (control i.e. no biofertilizer treated seeds), $T_{2}, T_{3}, T_{4}$ and $T_{5}$. In $T_{2}$, $\mathrm{T}_{3}$ and $\mathrm{T}_{4}$, seeds of black gram were inoculated with *Corresponding author three Rhizobium strains, respectively. In $\mathrm{T}_{5}$, three strains at a ratio of 1:1:1 was used for the inoculation of seeds. In each pot, 25-30 seeds were sown and the crop was always kept free from weeds. Results regarding different growth indices of two black gram varieties due to treatment with different Rhizobium strains are presented in Figs. 1-16. Variation in shoot length as was found in this study might be due to five different treatments with three Rhizobium strains. In both the varieties, $T_{5}$ always showed the higher values for shoot length compared to other treatments. Similar pattern of results regarding root length was observed. Patil and Shinde (1980) reported similar effect of Rhizobium inoculation in root and shoot length of black gram. In case of $\mathrm{T}_{5}$, it always showed higher values, which indicated beneficial effect of Rhizobium received by both the varieties in the present study. However, Pareek (1979) did not find any beneficial effect of inoculation for these characters of gram but Chahal and Rewari (1977) reported increased fresh weight of shoot due to five strains of mung bean Rhizobium under pot culture. There was a gradual increase of root dry weight with the increase of plant age and the roots were found to show more nodulation at the early stages of plant. It means less nodulation at the stage did not influence the root dry weight. Higher leaf dry weight in this study was found at 70 DAS in both the varieties. With the increase of plant age, values for this character were found to increase. Total leaf area due to five different treatments with Rhizobium strains was found to show both very high and very low values at the initial and the final stages of growth, respectively. In both the varieties, highest values for this character indicated no varietal differentiative response to Rhizobium strains. 

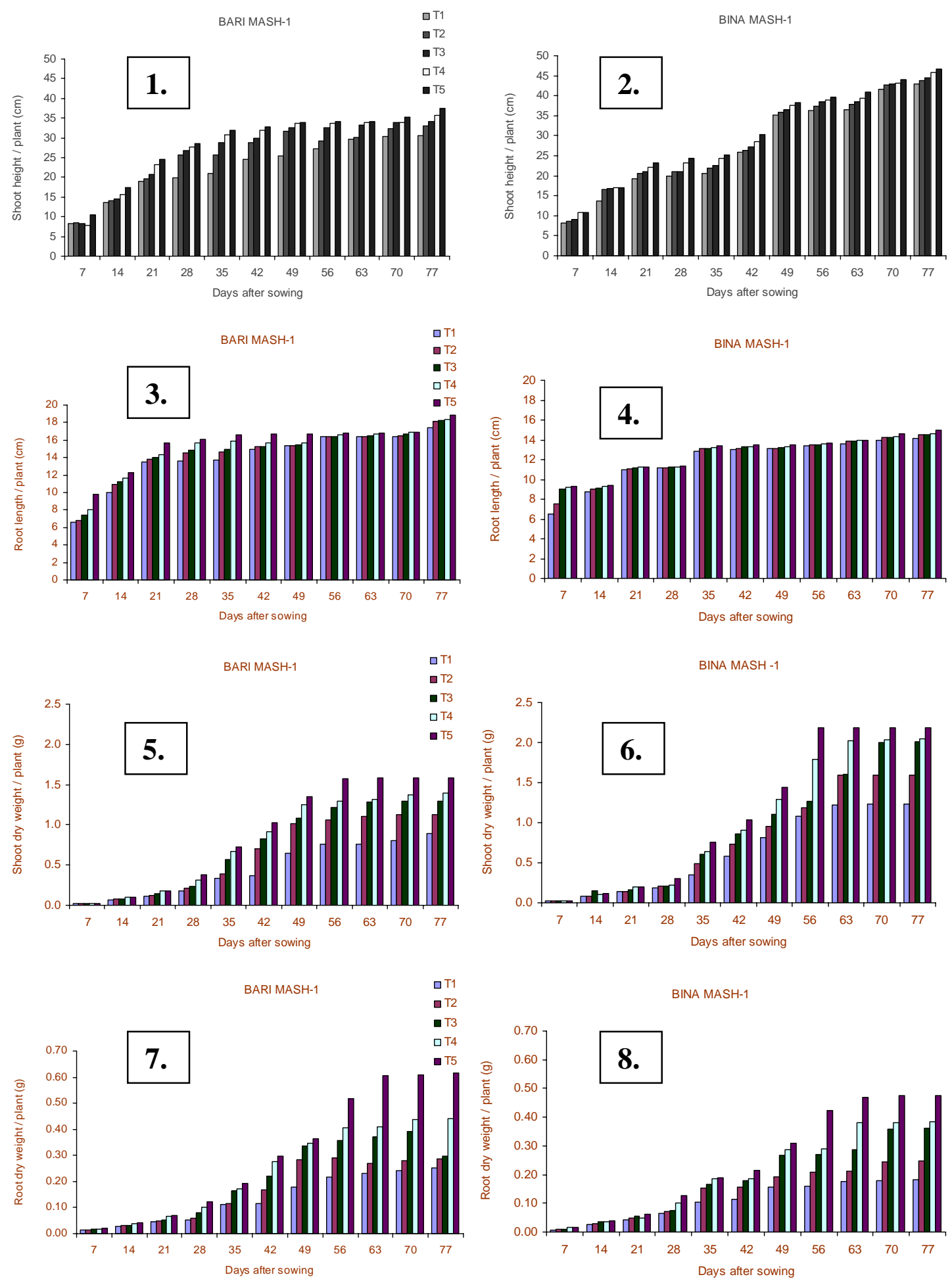

Figs. 1-8. Influence of five different treatments of Rhizobium strains on growth indices of two black gram varieties at different days after sowing (DAS). 1-2. Shoot height/plant, 3-4. Root length/plant, 5-6. Shoot dry weight/plant and 7-8. Root dry weight/plant. 

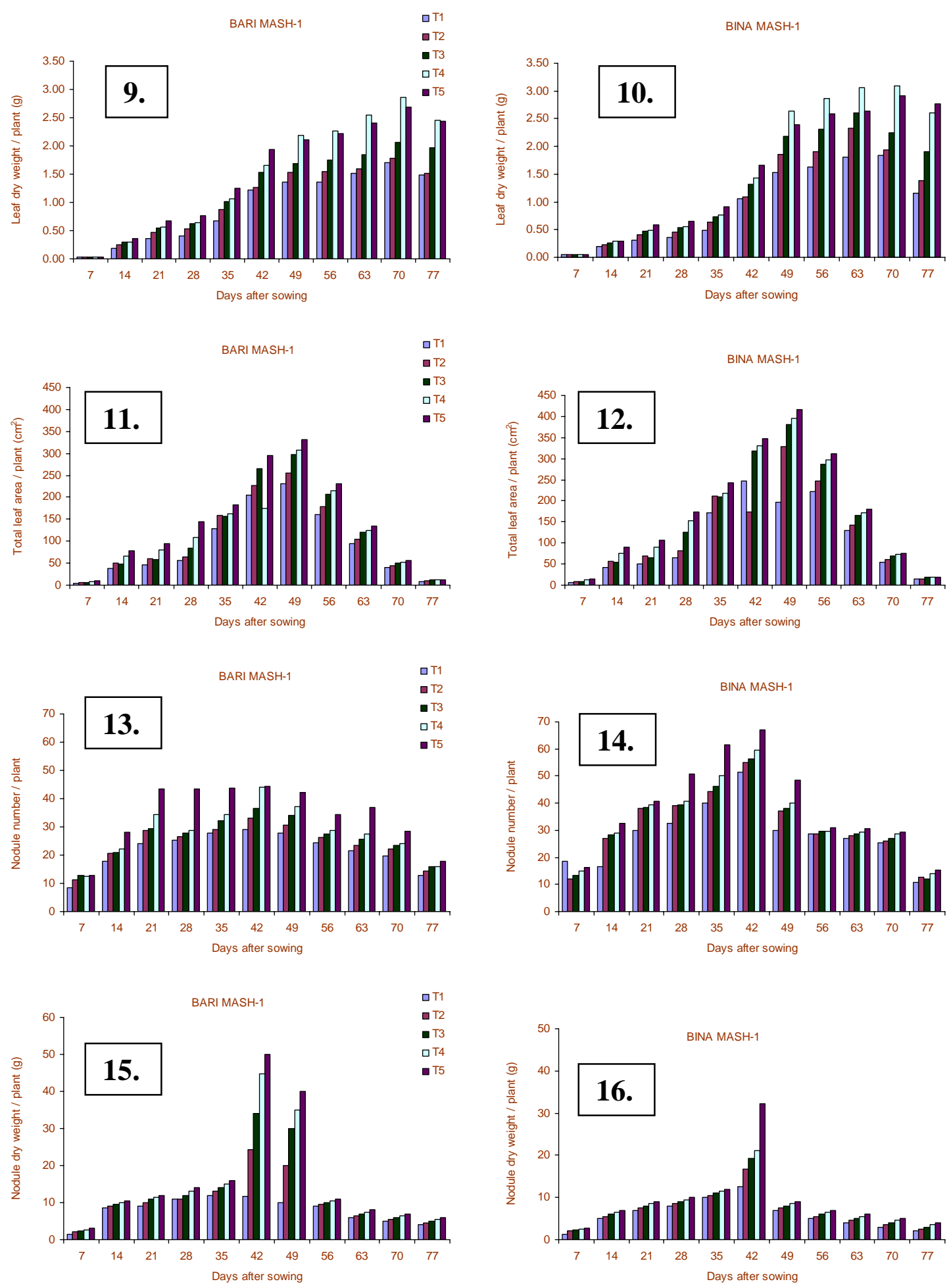

Figs. 9-16. Influence of five different treatments of Rhizobium strains on growth indices of two black gram varieties at different days after sowing (DAS). 9-10. Leaf dry weight/plant, 11-12. Total leaf area/plant, 13-14. Nodule number/plant and 15-16. Nodule dry weight/plant. 
In the present study, pattern of nodulation was not similar in both the varieties. It started with low values and increased very much at 42 DAS but declined gradually after that time and became very low at 77 DAS in BINA MASH-1. Rao and Venkateshwarlu (1983) studied the pattern of nodulation and nitrogen fixation in moth bean. They found different number of nodules in sixteen varieties of Vigna aconitifolia. Prasad et al. (1984) reported that number of nodules was found to increase with the increase of plant age and with nodule surface development. However, in the present experiment, Rhizobium strains were found to be most favourable for more nodulation in BINA MASH-1 compared to that of BARI MASH-1. Pawar and Ghulgule (1980) reported that in Vigna mungo nodules appeared 7 DAS and reached to the maximum number after 21 DAS. Almost equal number of nodules was observed from 21-42 DAS in BARI MASH-1 in the present study. The highest value for nodule dry weight/plant was found at 42 DAS in BARI MASH-1 and it decreased at 49 DAS. At the beginning, the values were very low for BARI MASH-1 and at the end, the values declined remarkably. Almost similar result was observed in BINA MASH-1 (Figs 15-16). Kumar Rao and Vishwanathan (1974) reported that 10 soybean cultivars inoculated with Rhizobium showed the highest dry weight of nodule/plant only in two cultivars. They also did not find any relation between number and dry weight of nodule per plant. However, in the present study, the highest value for this character was found in BARI MASH-1 compared to that of BINA MASH-1. Nodule dry weight may be considered as a useful character for selecting efficient strains of Rhizobium. Dry weight of nodules per plant compared to the number of nodules was more closely related to seed yield as reported by Khurana et al. (1984). This may also be used as a selection criterion for improvement in seed yield of black gram.

\section{References}

Chahal VPS and Rewari RB. 1977. Leghaemoglobin and bacteroid content in relation to nitrogen fixation J. Res. Punjab Agric. Univ. 14, 386-388.

David MS. 1991. Effect of solanization, Rhizobium inoculation, genotypic variation and $\mathrm{P}$ application on dry matter yield and utilization of P by pea (Pisum sativum L.) and lentil (Lens culinaris Medic) J. Nuclear Agril. and Biology 19(4), 227-231.

Khurana SR, Lakshminarayana K and Narule N. 1984. Response pattern of soybean (Glycine max) genotypes as influenced by nodulation traits. Indian J. Agric. Res. 18, 193-196.

Kumar Rao JVDK and Vishwanathan SR. 1974. Nodulation interaction between soybean genotypes and Rhizobium japonicum Curr. Res. 12, 163-164.

Nitu SK, Ud-deen MM and Haider SA. 2009. Effect of different Rhizobium strains on the growth attributes of black gram. J. Life Earth Sci., 3-4, 7-13.

Pareek RP. 1979. Studies on the effectiveness of different strains of chick pea Rhizobium in field Indian $\mathrm{J}$. Microbiol. 19, 123-129.

Patil RN and Shinde PA. 1980. Studies on nodulation pattern in gram (Cicer arietinum). J. Maharastra Agric. Univ. 5, 211-213.

Pawar NB and Ghulghule JN. 1980. Preliminary observations on occurrence and senescence of root nodules in some pulses. Trop. Grain Leg. Bulletin 17/18, 3-5.

Prasad R, Jamaluddin and Dadwal VS. 1984. The studies on nodulation behaviour in Lucaena leucocephala Indian Forester 110, 1149-1154.

Rao AV and Venkateshwarlu B. 1983. Pattern of nodulation and nitrogen fixation in moth bean. Indian J. Agric. Sci. 53, 10351038. 